\title{
The Action of some Denitrifying Bacteria in Tropical and Temperate Seas, and the Bacterial Precipitation of Calcium Carbonate in the Sea.
}

\author{
By
}

\author{
G. Harold Drew.
}

TABLE OF CONTENTS.

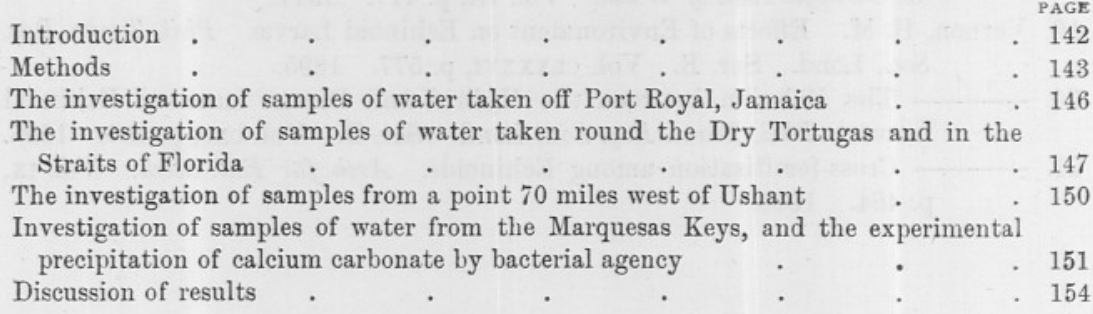

\section{INTRODUCTION.}

It is generally conceded that the plankton of tropical and sub-tropical seas is far less in quantity than that found in colder waters.

The zoö-plankton depends ultimately for its food on the phytoplankton; hence any factor limiting the growth of the phyto-plankton, which is capable of functioning in tropical and not in temperate or Arctic waters, might offer an explanation of this phenomenon. It has been shown by various investigators that this factor is not temperature, light, or salinity, and it has been suggested that the explanation may lie in the relative deficiency in tropical seas of the nitrates or nitrogenous compounds which are so essential for all plant life. A matter of common observation in support of this view is the remarkable scarcity of algal growth in the shallow waters of tropical shores as compared with that in similar situations in temperate regions, and the fact that in the tropics, wherever sewage or other nitrogenous waste is poured into the sea, a free growth of algæ is found.

At present no reliable and accurate chemical method of estimating the combined nitrogen in sea-water exists, hence this theory cannot be 
directly put to the test. On the other hand, the existence of denitrifying bacteria in temperate waters has long been known, and it would seem a fair deduction that should this bacterial destruction of nitrates take place with greater intensity and completeness in tropical than temperate waters, an explanation of the relative scarcity of plankton in the former would be offered, and it was with the object of investigating this question that the present work was undertaken.

My thanks are due to the Marine Biological Department of the Carnegie Institute of Washington, U.S.A., for their kindness in accommodating me in their Laboratory at Loggerhead Key, Dry Tortugas, and at their temporary Laboratory in Port Royal, Jamaica, B.W.I., and also to the Marine Biological Association of the United Kingdom for giving me facilities for work in their Plymouth Laboratory.

\section{METHODS.}

At the Dry Tortugas Laboratory, the motor-yacht Anton Dohrn enabled me to obtain samples of water from the middle of the Gulf Stream, and a number of smaller motor-boats were always available for shorter journeys. At Port Royal, Jamaica, it was necessary to depend on a sailing-boat, but owing to the remarkable regularity with which a breeze springs up every morning, no difficulty was encountered from this cause. At Plymouth the s.s. Oithona enabled me to obtain samples of water from a point seventy miles west of Ushant.

The observations were made at Port Royal during May, at the Tortugas during June, and at Plýmouth in August, 1911.

For purposes of comparison an endeavour was made in every case to obtain samples of water from localities where truly oceanic conditions prevailed, and hence samples were not obtained from the English Channel, where previous experience had shown that the bacterial flora was abundant and varied, owing to contamination from the land.

Surface samples were collected in sterilized wide-mouthed stoppered bottles holding about twelve ounces. Care was taken to avoid contamination from the sides of the boat by always collecting the samples from the bows when the boat was going ahead.

Deep samples were collected at the Tortugas in retort-shaped glass flasks of about 300 c.c. capacity, with narrow, recurved, longdrawn-out necks. These were sterilized, exhausted, and sealed: they were then lowered in an apparatus in which the extremity of the neck could be broken off at any desired depth by sending a messenger down the sounding wire, when the flasks became completely filled with 
water. After hauling up, a little water was shaken from the neck, and it was then sealed with the blow-pipe. By this method risk of contamination from more superficial layers of water as the apparatus is drawn up is avoided, since the changes in pressure and temperature as it ascends tend to cause a continuous outflow through the narrow neck until the surface is reached. The samples were taken back to the Laboratory, and cultures were made within three hours of collecting.

A somewhat similar apparatus was used for obtaining deep samples from the station seventy miles west of Ushant, but the glass bulbs were smaller and the tube leading from them was bent at right angles to itself. Considerable difficulty was caused by the breaking of the tube, owing to the force of the inrushing stream of water impinging on the wall where it was bent at right angles. After collecting the sample, the tubes were sealed with melted paraffin wax, and this method does not appear to have caused any bacterial contamination of the samples. Attempts to make Agar plate cultures in Petri dishes on board did not give satisfactory results, as, owing to the motion of the boat, the jelly set in irregular waves and lumps. Consequently the samples were kept in ice, and cultures were made from them at Plymouth twenty-four hours after collection. It is clear that if in the future attempts are made to make plate cultures on board a small boat, a very delicately swung table will be necessary, or else the roll tube culture method must be employed.

In Jamaica no apparatus for obtaining deep samples was available, so the primitive method of lowering a sterilized stoppered bottle with a string tied to the stopper was employed. At the required depth the stopper was pulled out until the bottle was nearly full, and then allowed to fall back in place. This method can only be used for very slight depths, owing to the pressure of the water at greater depths making it impossible to withdraw the stopper: a source of error also is introduced in that the inrushing water passes in close proximity to the stopper and its attachments, and may carry in bacteria which have adhered to them when passing through the surface layers.

The media most commonly employed for isolating the bacteria in plate cultures had the following composition :-

\section{Peptone Agar.}

Peptone . $2 \cdot 0$ grammes. Potassium nitrate $\left(\mathrm{KNO}_{3}\right)$ 0.5 Sea-water $1000 \cdot 0$ c.c. Agar Agar.

$12 \cdot 0$ grammes 
II. Potassium Malate Agar.

Potassium malate $\left(\mathrm{C}_{2} \mathrm{H}_{3}(\mathrm{OH})<\mathrm{COOK}\right.$
Sodium phosphate $\left(\mathrm{Na}_{2} \mathrm{HPO}_{4}, 12 \mathrm{H}_{2} \mathrm{O}\right)$
Potassium nitrate $\left(\mathrm{KNO}_{3}\right)$
Sea-water .

The medium was only filtered through glass wool, so that a very slight floccular precipitate of Calcium phosphate was retained.

For other purposes a simple solution of Peptone in sea-water was employed (2 grammes to 1000 c.c.), and media were also used consisting of this Peptone solution with the addition of 0.5 per cent of various carbohydrates, such as Cane-sugar, Dextrose, Laevulose, Mannite, Lactose, etc., with sufficient Neutral Red solution to colour them.

In the case of Gelatin media, it was necessary to keep them artificially cooled to a temperature of between $20^{\circ}$ and $25^{\circ} \mathrm{C}$, as in the Tortugas the Laboratory temperature occasionally rose as high as $37^{\circ}$ C., at which temperature Gelatin media will not remain solid.

When comparing various samples of water as to their power of causing denitrification in culture media, the following uniform method was employed :-

10 c.c. of each sample was added to 1000 c.c. of a modification of of Gran's medium (see Studien über Meeresbacterien, by H. H. Gran, Bergens Museums Aarbog, No. 3, 1901). This culture fluid was sterilized in glass flasks and has the following composition :-

Potassium nitrate $\left(\mathrm{KNO}_{3}\right)$. . . 0.5 grammes.

Sodium phosphate $\left(\mathrm{Na}_{2} \mathrm{HPO}_{4}, 12 \mathrm{H}_{2} \mathrm{O}\right)$. $0 \cdot 25$ grammes.

Calcium malate $\left(\mathrm{C}_{2} \mathrm{H}_{3}(\mathrm{OH})<\mathrm{COO}>\mathrm{Ca}\right)$. about $5 \cdot 0$ grammes.

Sea-water . . . . . $1000 \cdot 0$ c.c.

Calcium malate is only slightly soluble in water (about $\frac{1}{20}$ th per cent), and so can be added in excess.

The reduction of the nitrate to a nitrite was tested for by the addition of 5 c.c. of 10 per cent Sulphuric acid and 2 c.c. of a 1 per cent solution of Metaphenylene diamine hydrochloride to 25 c.c. of the culture. The production of a brown coloration (due to the formation of Bismark brown) is an indication of the presence of a nitrite, and is an extremely delicate reaction.

The formation of Ammonia was tested for by the addition of 5 c.c. of a 10 per cent solution of Potassium hydrate, and 5 c.c. of Nessler's reagent: the white precipitate formed on the addition of the Potassium 
hydrate does not appreciably interfere with the test, though it renders it somewhat less delicate.

The presence of nitrates or nitrites remaining in the culture fluid after the bacterial action was tested by the extremely delicate Brucine and Diphenylamine reactions.

\section{THE INVESTIGATION OF SAMPLES OF WATER TAKEN OFF PORT ROYAL, JAMAICA.}

In Jamaica, a measurement of the rate of denitrification in the modified Gran's medium inoculated with samples of sea-water was made, but the isolation of the bacteria on solid media was not attempted, owing to lack of apparatus.

Samples of sea-water were collected in sterilized stoppered bottles from the surface, and from depths of three and six fathoms, in positions about five miles from shore, where, from a consideration of the wind and tide, the water was probably under truly oceanic conditions, and unaffected by the neighbouring land.

The cultures were kept in a moderately dim light, and the room temperature ranged between $25^{\circ}$ and $31.5^{\circ} \mathrm{C}$. The average temperature during the growth of each culture was noted.

In a typical culture made from surface water, and for which the average temperature was $29^{\circ} \mathrm{C}$., the first indication of the formation of a nitrite, as given by the Metaphenylene diamine reaction, appeared after twenty-seven hours: after thirty-eight hours the brown colour produced in this reaction was very intense, the culture became cloudy, and on testing with Nessler's reagent, slight Ammonia formation was apparent. After forty-eight hours the culture became very cloudy and a scum of bacterial growth developed: the nitrite and Ammonia reactions remained unaltered. After sixty-three hours the nitrite reaction was somewhat less marked, the Ammonia reaction was unaltered, and bubbles of gas began to appear. After seventy-two hours many bubbles of gas were being produced and the nitrite and Ammonia reactions were very slight. After eighty-six hours the bubbling had ceased, and no nitrite or Ammonia was present in the cultures. Testing the culture for nitrates by the Diphenylamine and Brucine methods, showed that no nitrates or nitrites were left in the solution. In the absence of a gas analysis apparatus the nature of the gas evolved could not be exactly determined, but considering that it was non-inflammable, did not turn lime-water milky, and that the nitrate originally present had been destroyed, it seems strongly probable that this gas was pure Nitrogen.

Thus at a temperature of $29^{\circ}$ C., 0.5 grammes of Potassium nitrate 
were decomposed in eighty-six hours, and it was found that if a further 0.5 grammes of Potassium nitrate was added to the culture, it was in turn rapidly decomposed: this could be repeated indefinitely until the other constituents of the medium were used up, or the concentration of waste products became too high.

The rate of denitrification varied considerably with the temperature, and in cultures kept at a temperature between $10^{\circ}$ and $12^{\circ} \mathrm{C}$., no growth or denitrification occurred. Denitrification was more rapid in cultures from water taken from a depth of three or six fathoms than from the surface. It was also especially rapid with samples taken from the thick, muddy waters of a mangrove swamp, where organic matter was plentiful.

The bacteria present in the cultures were very minute, actively motile bacilli with rounded ends.

\section{THE INVESTIGATION OF SAMPLES OF WATER TAKEN ROUND THE DRY TORTUGAS AND IN THE STRAITS OF FLORIDA.}

Cultures made in the modified Gran's medium from various positions round the Tortugas gave results in close accord with those found in Jamaica, and the average rate of denitrification was the same; hence it appears probable that much the same bacterial conditions obtain in both places. Cultures were made on various solid media, and pure cultures of the bacteria were isolated. Petri dishes with porous earthenware covers were used and were found of great advantage, as by this means the formation of drops of water on the covers is prevented, and the water of condensation evaporates as soon as formed: in addition a free air supply is ensured. If evaporation is progressing too rapidly, the whole Petri dish can be covered with a bell-jar lined with damp filter-paper after the first day.

By plating samples of surface water from various positions as far as possible removed from the influence of the land, an average of fourteen colonies per 1 c.c. sea-water was obtained. These colonies appeared to be of two kinds, one much more plentiful than the other. Subcultures made from these colonies in Gran's medium showed that the bacteria forming the most common type of colony produced an active denitrification, while the others grew very slowly in this medium, and produced no denitrification. The chief characteristics of the denitrifying form are as follows:-

On the Potassium malate, or Peptone Agar media, colonies are visible as minute white specks after six to eight hours, when the 
room temperature averages $29.5^{\circ} \mathrm{C}$. After about eighteen hours the colonies are well developed, they are white in colour, circular, but with finely irregular outline, and have a granular appearance. Superficial colonies are much elevated at first, but as growth proceeds, spread rapidly over the surface of the Agar. The deep colonies remain small, circular, and discrete. Growth is somewhat more rapid on the Peptone Agar than on the Potassium malate Agar, and the older colonies develop a brownish tinge in the centre when growing on the former medium.

On Gelatin Peptone ( 5 per cent Peptone, kept at between $20^{\circ}$ and $25^{\circ} \mathrm{C}$. to ensure the medium remaining solid) growth was very slow; in stab cultures growth proceeded slowly from the surface downwards, forming a funnel-shaped depression of liquefied gelatin. Acid formation occurs in Glucose, Mannite, and Canesugar, but not in Lactose media.

Growth is totally inhibited at a temperature of $10^{\circ} \mathrm{C}$., but takes place slowly at $15^{\circ} \mathrm{C}$.

Growth is much retarded by exposure to bright sunlight, but the bacteria are not killed by a ten hours' exposure.

The bacteria are facultative anaërobes, but growth under anaërobic conditions is very slow.

In Gran's medium growth and denitrification are rapid, but no growth occurs if the Potassium nitrate be omitted, or if the Calcium malate be replaced by Calcium carbonate. Growth in a pure solution of Peptone in sea-water is very slight, but becomes abundant if Potassium nitrate be added, when denitrification quickly ensues.

In its cultural reactions this bacterium is very similar to certain denitrifying forms found in the English Channel. The chief points of difference consist in its much greater denitrifying power, and the higher temperature necessary for its growth, by which it would be prevented from spreading into colder waters.

The characteristics of the scarcer, non-denitrifying, form of bacterium found on the Peptone Agar plates made from surface samples are as follows :-

Growth on the Potassium malate Agar medium is very slow and indefinite. On Peptone Agar growth is somewhat slower than in the case of the denitrifying form. On the surface, circular creamcoloured colonies are formed having a brownish centre, the edges are smooth and regular, and the colony remains discrete and does not tend to spread over the surface. The deep colonies are 
smaller and usually ovoid in shape, and of a somewhat darker colour than those on the surface. Growth does not occur on gelatin media.

Acid formation takes place in Glucose, but not in Cane-sugar, Lactose, or Mannite media.

Growth is much retarded by exposure to a strong light, and cultures on sloped Peptone Agar are completely killed by four hours' exposure to bright sunlight.

The bacterium is a strict aërobe.

Free growth takes place in Gran's medium, but develops much slower than in the case of the denitrifying form : no growth occurs if the Potassium nitrate be omitted entirely, but takes place freely if a mere trace in excess of that normally present in the sea-water be added, though no denitrification results. Attempts were made to discover whether this bacterium had any nitrifying or denitrifying action in various culture media, but uniformly negative results were obtained. Nitrites were neither oxidized to nitrates, nor reduced to Ammonia or free Nitrogen, and Ammonium salts were unaffected. No growth was obtained in any culture medium that did not contain at least a trace of nitrates, so it was not practicable to ascertain whether the bacterium had a nitrifying action without the necessary facilities for quantitative work.

On one occasion samples were obtained from various depths up to 90 fathoms at a point in the Gulf Stream, 25 miles south of the Dry Tortúgas.

The samples were plated in the Peptone Agar medium, and counted with the following average results :-

\begin{tabular}{|c|c|c|c|}
\hline $\begin{array}{c}\text { Depth } \\
\text { fathoms. }\end{array}$ & $\begin{array}{c}\text { Denitrifying } \\
\text { forms. }\end{array}$ & $\begin{array}{c}\text { Non-denitrifying } \\
\text { forms. }\end{array}$ & $\begin{array}{c}\text { Number of colonies developing } \\
\text { from 1 c.c. of sample. }\end{array}$ \\
\hline 0 & 9 & 2 & 11 \\
\cline { 1 - 2 } 10 & 25 & 4 & 29 \\
40 & 2 & 2 & 4 \\
60 & 5 & 3 & 8 \\
90 & 5 & 6 & 11 \\
\hline
\end{tabular}

If any deductions can be made from one series of observations, it would seem probable that the non-denitrifying bacteria are a deep- 
water form, and this would be upheld by the ease with which they are killed by exposure to sunlight. On the other hand, the denitrifying bacteria would appear to be a surface form, reaching their maximum a little below the surface. This would be substantiated by the results obtained in Jamaica, by which it was shown that denitrification occurred much more rapidly in cultures made from samples collected at depths of 3 and 6 fathoms, and might possibly be explained by the fact that the growth of the bacteria is inhibited by strong light.

\section{INVESTIGATION OF SAMPLES FROM A POINT 70 MILES WEST OF USHANT.}

The samples were plated in the Peptone Agar medium after having been kept on ice for twenty-four hours, for the reason previously explained.

The colonies were well developed after forty-eight hours, and appeared to be all of one kind. A count gave the following average results :-

Depth in fathoms.

Number of colonies developing

$\begin{array}{rrrrrrrr}0 & \ldots & \ldots & \ldots & \ldots & \ldots & \ldots & 7 \\ 10 & \ldots & \ldots & \ldots & \ldots & \ldots & \ldots & 9 \\ 20 & \ldots & \ldots & \ldots & \ldots & \ldots & \ldots & 6 \\ 30 & \ldots & \ldots & \ldots & \ldots & \ldots & \ldots & 5 \\ 50 & \ldots & \ldots & \ldots & \ldots & \ldots & \ldots & 6 \\ 70 & \ldots & \ldots & \ldots & \ldots & \ldots & \ldots & 30 \\ 80 & \ldots & \ldots & \ldots & \ldots & \ldots & \ldots & 20\end{array}$

The increase in the number of colonies at 70 and 80 fathoms is somewhat remarkable, but no conclusions in this respect can be drawn from one series of observations:

The appearance and cultural characteristics of the bacterium obtained from these samples were identical with those of the denitrifying form investigated at the Tortugas, with the exception that acid formation did not take place in media containing Cane-sugar.

1000 c.c. of the modified Gran's medium inoculated on board with 10 c.c. of a surface sample immediately after collection, and kept at an average temperature of $20^{\circ} \mathrm{C}$., showed the first trace of nitrite formation after $\mathbf{7 0}$ hours. After 84 hours a very strong nitrite reaction was obtained, and a slight Ammonia reaction was given with Nessler's reagent. The process of denitrification, even after the lapse of weeks, did not extend beyond this, and no bubbles of gas were formed. Other experiments made with subcultures from Agar and Gelatin media gave similar results, so that it appears that this bacterium cannot entirely 
break down nitrates at a temperature of $20^{\circ} \mathrm{C}$. The optimum temperature for denitrification produced by this bacterium appears to be about $20^{\circ} \mathrm{C}$., as the process was less rapid at average temperatures of $17^{\circ} \mathrm{C}$. and $25^{\circ} \mathrm{C}$. At a temperature of $32^{\circ} \mathrm{C}$. rapid growth took place, but no denitrification resulted.

It should be noted that these temperature observations were only made with subcultures from colonies on Peptone Agar and Peptone Gelatin media, and there is reason to believe that the power of denitrification becomes diminished after cultivation on such media. Further and more accurate temperature experiments are required, in which the culture medium is directly inoculated with freshly collected samples of water.

INVESTIGATION OF SAMPLES OF WATER FROM THE MARQUESAS KEYS, AND THE EXPERIMENTAL PRECIPITATION OF CALCIUM CARBONATE BY BACTERIAL AGENCY.

The Marquesas Keys constituie a coral atoll which forms part of the long chain of Keys separating the Gulf of Mexico from the Straits of Florida. Within the atoll the water is very shallow, and the bottom consists of a fine chalky mud many feet deep. Samples of the water from within the atoll were sent to me at Plymouth by post, and examined fourteen days after collection.

On plating on Peptone Agar, 800 colonies per 1 c.c. of the sample were obtained. These colonies appeared to be all of one species, and in appearance and all cultural characteristics were identical with the denitrifying form previously described as occurring around the Tortugas.

A suspension of these bacteria from a culture on Peptone Agar was made in sterile sea-water, and a similar suspension, containing roughly the same number of bacteria, was made from a third subculture on Peptone Agar of the bacteria obtained from the station seventy miles west of Ushant. 1 c.c. of each of these suspensions was then added to 1000 c.c. of the modified Gran's medium; some of these cultures were kept at an average temperature of $20^{\circ} \mathrm{C}$. and others at $32^{\circ} \mathrm{C}$., with the following results:-

At $20^{\circ} \mathrm{C}$. cultures from Marquesas showed trace of nitrite after 45 hours.

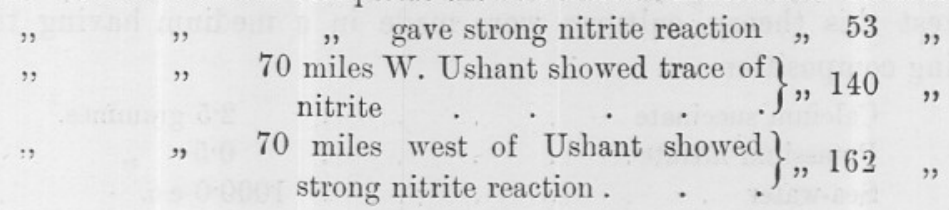


In both cases a slight amount of Ammonia was recognizable by Nessler's reagent when the nitrite reaction was strong, but decomposition of the nitrite did not proceed further even after fourteen days.

At $32^{\circ}$ C. cultures from the Marquesas showed trace of nitrite after 18 hours.

$" \quad, \quad$ " $\quad 70$ miles west of Ushant never gave
nitrite or Ammonia reactions.

The cultures from the Marquesas showed a slight amount of Ammonia formation, but the decomposition of the nitrite did not proceed further.

From these experiments it appears that the bacteria from subcultures from the Marquesas have a much greater denitrifying power than those from subcultures from a point seventy miles west of Ushant, and that as the bacteria from the Marquesas appear to be of the same species as those investigated at the Dry Tortugas, their power of causing complete denitrification in the modified Gran's medium has been lost by cultivation on Peptone Agar, or during the fourteen days journey from the Marquesas.

The presence of the thick layers of fine chalky mud within the Marquesas Keys, and elsewhere in many places near the Florida coast, led to a consideration of the possibility of its precipitation by bacterial agency.

Since these bacteria grow freely in Gran's medium, the Calcium salt of a simple organic acid is a sufficient source of organic food for them, and it seems probable that they would thrive in sea-water containing the products of decomposing vegetable matter, provided that the nitrate supply and conditions of light and temperature were suitable. Such conditions should be especially, well fulfilled by the drainage into the sea of a well-wooded country with a calcareous subsoil, and the soluble organic Calcium salts carried to the sea in this way, would there be precipitated as Calcium carbonate by the action of the bacteria. In addition, the elimination of the acid radicle from the nitrate in the process of denitrification, by whatever stages it may occur, must leave the alkaline base free to destroy the normal equilibrium of the salts in sea-water, and by increasing the alkalinity, would also result in the precipitation of Calcium carbonate.

To test this theory, cultures were made in a medium having the following composition :-

Calcium succinate

Potassium nitrate.

Sea-water

2.5 grammes.

0.5 ,

1000.0 c.c. 
Calcium succinate is soluble in these proportions, and the medium is quite clear. Free growth was manifested by the cloudiness of the medium forty-eight hours after inoculation, and nitrite formation was apparent. After ninety-six hours the medium appeared quite milky, and this milkiness was due to the presence of exceedingly fine particles of a substance which was soluble in dilute hydrochloric acid with evolution of gas, and was presumably Calcium carbonate. These particles were so minute that they remained in suspension in the liquid, and could only be satisfactorily separated from it by centrefugalizing. The addition to this culture of very fine particles of hydrated Calcium sulphate, or of larger particles of sand, resulted in the aggregation around them of the particles of Calcium carbonate, forming a concentrically laminated concretion around a central nucleus. These concretions were hard, and of almost crystalline appearance under the microscope, and were soluble in dilute Hyd̉rochloric acid with evolution of bubbles of a gas which when the operation was performed on a microscopic slide, could be completely absorbed by running in a solution of Sodium hydrate under the cover slip. Once this process of concretion has been initiated, it appears to progress independently of the presence of particles which act as nuclei, and a large concretion may often be found having a number of smaller concretions around it, or continued into a chain of small spheres, the whole presenting somewhat the arrangement shown by freely budding yeast cells. The deposition of this form of Calcium carbonate also takes place on the sides of the flask, and more especially over any area where the glass is scratched or roughened.

It would seem a reasonable suggestion that similar bacterial agency may have played a part in the formation of oölitic limestones, which are composed of concretions of Calcium carbonate around central nuclei often consisting of particles of sand or shells. In the same way bacterial action may have been of great importance in the precipitation of the various chalk strata, and indeed in the formation of many rocks largely composed of Calcium carbonate.

If this view as to chalk and oölitic limestone formation is correct, it would seem probable that the precipitation of these rocks must have occurred in comparatively shallow seas, which received the drainage from a country in which extensive weathering of rocks containing Calcium salts was progressing, and where there was a considerable amount of vegetation from the decay of which the organic matter necessary for bacterial growth would be derived. 


\section{DISCUSSION OF RESULTS.}

It seems that the rate of denitrification in equal volumes of the same culture medium, inoculated with equal volumes of samples of sea-water, must be a function of the number of bacteria in the sample, the temperature at which the cultures are grown, and the specific power of denitrification of the individual species of bacteria. Considering the rapid multiplication of bacteria when the food supply is plentiful, up to a maximum determined chiefly by the accumulation of the waste products of their own metabolism, it appears that the factor of the number of bacteria in the sample may be neglected within the limits of these experiments. For example, the number of bacteria in 1000 c.c. of Gran's medium at the end of twenty-four hours would probably be much the same, whether it were inoculated from a sample containing eight or sixteen bacteria per 1 c.c. Similarly, it was a matter of experience that the first trace of nitrite formation was observable at about the same time, whether 5 or 10 c.c. of a given sample had been used for inoculation.

Consequently it appears that, for purposes of comparison, and within the limits of the experiments described, if the temperature be the same for the cultures compared, the rate of denitrification is a measure of the specific denitrifying power of the particular species of bacteria.

Thus it has been shown that in cultures grown at temperatures approximating that of their normal environment, the denitrifying power of bacteria in seas in the American tropics is considerably greater than that of bacteria in the water to the north of the Bay of Biscay, and that they have the power under favourable conditions of completely breaking down nitrates, which those from the Bay of Biscay do not possess.

It has also been shown that these bacteria possess the power of precipitating Calcium carbonate from solutions of simple organic Calcium salts, and it is here suggested that some similar action has played an important part in geologic times in the precipitation of various rocks, wholly or in part composed of Calcium carbonate.

Investigation and comparisons of denitrifying power of samples of the coastal waters of the English Channel have been purposely avoided, as previous experience had shown that the bacterial conditions in this region are so very complicated. It should, however, be mentioned that in this coastal water denitrifying bacteria are present which are capable of entirely decomposing nitrates into free Nitrogen, e.g. the Bacillus repens (Gran), but that this complete denitrification is only possible at a temperature far higher than that of their normal environment, and that at a temperature of $15^{\circ} \mathrm{C}$. even the forma- 
tion of nitrite from the nitrate takes place with considerable slowness.

A point that has not yet been considered is the origin of the nitrate supply in the sea. Nitrates are absorbed by diatoms and the phytoplankton in general, and are presumably built up into complex nitrogenous compounds within the plant. If these compounds, on the death of the plant, are broken up and the Nitrogen again rendered available for use in the form of nitrates, a series of reactions must be gone through which may well be performed by bacterial agency, and this also applies to the waste nitrogenous products of animal metabolism. In addition, it has been shown that nitrates are actually destroyed by the denitrifying bacteria, which would thus tend to keep the nitrate concentration down to the level necessary for their own existence, and would come into competition for this essential with other forms of plant life. If the bacteria are successful in decomposing nitrates to the extent of entirely removing the Nitrogen from all chemical combination, as seems probable from the experiments in cultures, it follows that there must be some source of nitrates in order that the concentration in the sea may remain constant. The existence of nitrifying bacteria, which are capable of oxydizing the Nitrogen of the air to form nitrates, and are symbiotic with some of the Algæ found round the shores of the North Sea, has already been demonstrated, and it seems possible that forms having a similar nitrifying action remain to be discovered in the open sea.

As they at present stand, the observations noted in this paper can at most be considered as offering a slight indication of the part played by certain bacteria in the metabolism of the sea.

To obtain a real insight into the question, it would be necessary to make extensive bacterial and chemical investigations in tropical, temperate, and Arctic seas, and more especially to make a study of the bacterial flora at different depths at some spot where considerable depth, unaffected by currents, could be obtained. The probability that bacterial growth plays an important part in causing the precipitation of certain bottom deposits in coastal waters, and conceivably also in the deep sea, is a subject that appears well worthy of further investigation. 